\title{
PERTUMBUHAN POPULASI BULU BABI (Echinometra mathaei) DI PERAIRAN PESISIR KIMA BAJO KABUPATEN MINAHASA UTARA
}

\author{
Ruddy Djonie Moningkey \\ Staf Pengajar pada Program Studi Manajemen Sumberdaya Perairan, \\ Fakultas Perikanan dan IImu Kelautan. UNSRAT. Manado 95115.
}

\begin{abstract}
Sea urchins of different colors were collected 50 individuals each and measured their morphological characters. The data were then transformed to natural logarithm and analyzed using regression.

The comparison of the regression line intercept for the shell diameter-height relationship did not show any difference, but there was a significant difference for the shell lenght-heigth relationship. The comparison between different colors exhibited variations in the shell morphology of each sea urchin population.

The growth of black spined-sea urchin (Echinometra mathaei), was negative allometric; the fact that they were mostly found in the narrow crevices might have influenced their growth.
\end{abstract}

Keywords: Population growth, sea urchin, Echinometra mathaei, Kima Bajo.

\section{PENDAHULUAN}

Bulu babi merupakan penentu kelimpahan dan sebaran tumbuhan laut di perairan laut dangkal (Lawrence, 1975). Agregasi yang padat dari bulu babi bertanggung jawab atas hancurnya komunitas ganggang laut dan rusaknya komunitas lamun di beberapa daerah pantai di daerah tropis dan subtropis (Valentine dan Heck, 1991).

Bulu babi biasanya hidup mengelompok tergantung dari jenis habitatnya. Di sepanjang perairan pantai hewan ini memiliki variasi spesies yang cukup besar dan melimpah (Arakaki dan Uehara, 1991). Grazing bulu babi mempunyai pengaruh biologi dan ekologi yang penting pada Komunitm terumbu karang (Lawrence, 1975; Birkeland, 1988). Menurut Lawrence dan Sammarco (1982), beberapa spesies bulu babi menyebabkan bioerosi bersubstrat kapur di daerah rataan terumbu karang dan bersubsrat keras (berbatu), daerah intertidal dan subtidal.

Uehara dkk., (1990) telah melakukan pemeriksaan terhadap kromosom Echinometra mathaei di rataan terumbu karang Okinawa Jepang dan menyimpulkan bahwa spesies ini menunjukkan variasi warna yang sangat besar yang kemudian dikelompokkan ke dalam empat tipe bulu babi Echinometra mathaei yaitu Tipe A, B, C dan D. Di Sulawesi Utara baru ditemukan dua tipe yaitu Tipe $A$ dan $C$ dimana sesuai ciriciri yang diberikan oleh Nishihira dkk., (1991), cangkang bulu babi Echinometra mathaei Tipe A berukuran lebih besar daripada Tipe C. Perbedaan ini berhubungan dengan strategi hidup dan mencari makan dari bulu babi. Tipe C mempunyai kebiasaan meliang dan menunggu makanan yang terperangkap dalam liang, sedangkan Tipe A mempunyai kebiasaan aktif mencari makan pada daerah goba yang ditumbuhi alga dan lamun. Penelitian ini difokuskan pada pertumbuhan relatif Echinometra mathaei (de Blainville, 1825) tipe $C$ di rataan terumbu pantai Kima Bajo, Kecamatan Wori, Kabupaten Minahasa".dengan tujuan untuk menganalisis variasi pertumbuhan antar warna (merah muda, hitam, coklat, putih dan hijau) dari populasi bulu babi Echinometra mathaei tipe C.

\section{METODE PENELITIAN}

\section{Lokasi Pengambilan dan Pengukuran Sampel}

Pengambilan sampel bulu babi Echinometra mathaei Tipe C dilakukan dengan cara survei jelajah, dimana sampel yang diambil untuk tiap warna (merah muda, hitam, coklat, putih dan hijau) masingmasing 50 individu. Pengambilan sampel dilakukan pada saat surut terendah. 


\section{Pertumbuhan Populasi Bulu Babi}

Pengukuran karakter morfometrik menggunakan Vernier Callipers berketelitian $0,01 \mathrm{~mm}$, yang meliputi panjang cangkang (tanpa duri) pada bagian ambitus, lebar yang diukur dari ukuran yang terkecil dari panjang, dan tinggi yang diukur dengan arah tegak lurus sepanjang oralaboral. Diameter cangkang diambil dari dua ukuran yaitu ukuran terlebar (panjang) dan ukuran yang tersempit (lebar) kemudian dibagi dua $((\mathrm{P}+\mathrm{L}) / 2)$.

\section{Analisis Data}

Teknik analisis allometrik untuk menelaah pertumbuhan relatif berbagai bagian tubuh suatu organisme dengan persamaan perpangkatan (Huxley (1932):

$$
\mathrm{Y}=a \mathrm{x}^{\mathrm{b}}
$$

dimana (a) dan (b) adalah konstanta regresi, sedangkan $(\mathrm{Y})$ ialah variabel acak tidak bebas (data tinggi dan lebar cangkang); (x) adalah variabel acak/ terkontrol bebas (data diameter dan panjang cangkang).

Dugaan parameter (a) dan (b) diperoleh dengan merubah persamaan perpangkatan ke dalam bentuk penjumlahan melalui transformasi logaritma natural (Ln) sehingga membentuk persamaan garis sebagai berikut:

$$
\operatorname{Ln} Y=\operatorname{Ln} a+b \operatorname{Ln} X
$$

Untuk membandingkan kemiringan dan menguji perbedaan perpotongan garis regresi pada dua populasi digunakan uji peragam atau analisis kovarian (Scherrer, 1984). Hipotesa kesamaan kemiringan diperiksa dengan uji $\mathrm{Fvm}=\mathrm{S}^{2} \mathrm{vm} / \mathrm{S}^{2} \mathrm{gs}$, sedangkan hipotesa kesamaan perpotongan garis diperiksa dengan uji $F v 1=S^{2} V_{1} / S^{2} g s$. Jika nilai $F_{\text {hit }}>F_{\text {tab }}(\alpha=0,05$ hipotesa kesamaan kemiringan atau kesamaan garis perpotongan (intersep) ditolak, dalam hal sebaliknya diterima jika nilai $\mathrm{F}_{\text {hit }}<\mathrm{F}_{\text {tab }}(\alpha=0,05)$.

Untuk menguji apakah nilai $b=1$ (nilai teoritis) pada persamaan panjang-lebar cangkang dan nilai $b=1$ (nilai teoritis) pada persamaan perpangkatan tinggi-diameter cangkang digunakan Uji-t. Jika nilai $b=$ nilai teoritis maka pola hubungan disebut isometrik. Sedangkan allometrik negatif jika $b<$ nilai teoritis dan allometrik positif jika sebaliknya. Uji-t digunakan untuk melihat pola pertumbuhan berdasarkan Effendie (1979) yaitu:

$$
\mathrm{T}_{\text {hit }}=\left|\frac{1-\mathrm{b}}{\mathrm{sb}}\right|
$$

Kemudian untuk hubungan diameter cangkang-tinggi cangkang dan hubungan panjang cangkang-lebar cangkang menggunakan regresi linier:

$$
Y=a+b x
$$

\section{HASIL DAN PEMBAHASAN}

\section{Hubungan Antara Diameter Cangkang dan Tinggi Cangkang}

Bentuk kepipihan cangkang (bentuk kubah) masing-masing populasi warna duri Echinometra mathaei yang ditentukan dengan hubungan diameter dan tinggi cangkang menunjukkan nilai yang tidak bervariasi. Hasil pengambilan sampel sebanyak 50 individu dari masing-masing populasi warna diperoleh kisaran ukuran diameter cangkang populasi warna merah muda 26,55-37,44 mm, warna hitam 18,67$40,26 \mathrm{~mm}$, warna coklat 22,12-38,49 $\mathrm{mm}$, warna putih $21,81-37,32 \mathrm{~mm}$ dan warna hijau 22,75-36,96. Kisaran ukuran tinggi cangkangnya adalah 15,85-24,92 mm untuk warna merah muda, 10,85-25,34 mm untuk warna hitam, 12,19-25,87 mm untuk warna coklat, 12,59-25,35 mm untuk warna putih dan 12,29-23,70 mm untuk warna hijau.

Hasil analisis regresinya menurut populasi warna duri yang diperoleh dalam bentuk transformasi logaritma natural dan kurva perpangkatannya adalah sebagai berikut:

Tabel 1. Analisis regresi populasi warna duri.

\begin{tabular}{lll}
\hline Merah muda : & LnT $=-0,926+1,136 \mathrm{LnD}$ & $(n=50 r=0,89)$ \\
& $\mathrm{T}=0,396 \mathrm{D}^{1,136}$ & \\
\hline Hitam : & $\mathrm{LnT}=-1,217+1,222 \mathrm{LnD}$ & $(n=50 r=0,94)$ \\
& $\mathrm{T}=0,296 \mathrm{D}^{1,222}$ & \\
\hline Coklat : & $\mathrm{LnT}=-1,064+1,171 \mathrm{LnD}$ & $(n=50 r=0,91)$ \\
& $\mathrm{T}=0,345 \mathrm{D}^{1,1 / 1}$ & \\
\hline Putih : & $\mathrm{LnT}=-0,555+1,021 \mathrm{LnD}$ & $(n=50 r=0,81)$ \\
& $\mathrm{T}=0,574 \mathrm{D}^{1,027}$ & \\
\hline Hijau : & $\mathrm{LnT}=-1,320+1,248 \mathrm{LnD}$ & $(n=50 r=0,88)$ \\
& $\mathrm{T}=0,267 \mathrm{D}^{1,218}$ & \\
\hline
\end{tabular}

Hasil perhitungan koefisien korelasi (r) antara hubungan diameter-tinggi cangkang pada kelima populasi warna duri Echinometra mathaei menunjukkan nilai yang cukup besar (mendekati nilai 1) dan positif. Nilai $r$ yang mendekati 1 ini memberikan arti bahwa kedua data ini (diameter-tinggi cangkang) memiliki hubungan pendugaan 
yang sangat kuat (erat). Sedangkan nilai positif menunjukkan bahwa setiap pertambahan ukuran diameter cangkang maka ukuran tinggi cangkang akan mengalami pertambahan. Gambar 1 memperlihatkan hubungan antara tinggi cangkang pada sumbu $Y$ dan diameter cangkang pada sumbu $X$ dari kelima populasi warna duri bulu babi Echinometra mathaei tipe $\mathrm{C}$.

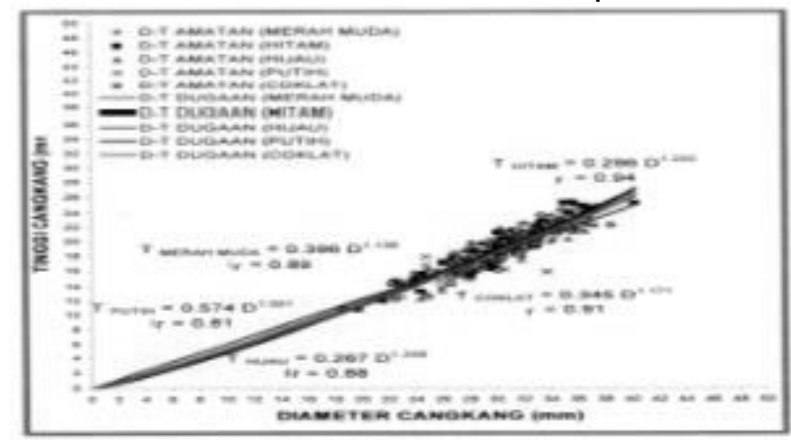

Gambar 1. Model hubungan diameter-tinggi cangkang bulu babi Echinometra mathaei tipe C dari semua warna duri.

Hasil analisis keragaman hubungan diameter-tinggi cangkang bulu babi Echinometra mathaei tipe $\mathrm{C}$ masing-masing populasi warna menunjukkan bahwa nilai $F_{\text {hit }}$ setiap data populasi warna duri $>\mathrm{F}_{\operatorname{tab}(0,05 ; 1 ; 48) \text {, yang }}$ memberikan arti bahwa data diameter cangkang dapat digunakan untuk menduga data tinggi cangkang sampai pada tingkat peluang 95\%. Hasil perhitungan tambahan terhadap error ketidakpasan model menunjukkan bahwa nilai $\mathrm{F}_{\text {hit }}<\mathrm{F}_{\operatorname{tab}(0,05 ; 2 ; 42)}$. Hasil ini menunjukkan bahwa data pengamatan dapat digunakan pada model perpangkatan (model yang dilinierkan).

Tabel 2 menunjukkan hasil perhitungan analisis peragam untuk membandingkan kemiringan dan menguji perbedaan intersep garis regresi antar populasi Echinometra mathaei dengan warna duri yang tidak sama. Hasilnya memperoleh bahwa dari sepuluh pasangan perbandingan populasi tersebut tidak menunjukkan perbedaan yang nyata baik untuk uji kemiringan maupun uji intersepnya.

Berdasarkan uji t (Tabel 3) menunjukkan bahwa populasi bulu babi Echinometra mathaei dari lima warna duri (merah muda, hitam, coklat, putih dan hijau) memiliki nilai $\mathrm{t}_{\text {hit }}<\mathrm{t}_{\mathrm{tab} 0,05(1 ; 48)}$. Hal ini menunjukkan bahwa pola pertumbuhan berdasarkan hubungan diameter-tinggi cangkang kelima populasi adalah isometrik. Artinya bahwa pertambahan diameter dan tinggi cangkang berjalan dengan laju yang serasi atau seimbang dimana proporsi tinggi cangkang tidak menunjukkan variasi yang sangat nyata dengan bertambahnya diameter cangkang. Dengan kata lain tidak ada perubahan bentuk kubah selama partumbuhan bulu babi Echinometra mathaei tipe C.

Tabel 2. Perbandingan parameter regresi diameter dan tinggi cangkang ( $T=a D b)$ dengan analisis peragam.

\begin{tabular}{lccccc}
\hline \multirow{2}{*}{ Populasi } & \multicolumn{2}{c}{$\mathbf{F}_{\text {hit }}$} & $\mathbf{F}_{\text {tab }}$ & \multirow{2}{*}{$\boldsymbol{B}$} & $\mathbf{a}$ \\
\cline { 2 - 3 } & $\mathbf{F ~ v m}$ & $\mathbf{F v}_{\mathbf{i}}$ & $\mathbf{( 0 , 0 5 : 1 , 4 8 )}$ & & \\
\hline Merah muda-hitam & 0,524 & 1,092 & 3,96 & Tn Tn \\
Merah muda-coklat & 0,082 & 3,386 & 3,96 & Tn Tn \\
Merah muda-putih & 0,543 & 2,773 & 3,96 & Tn Tn \\
Merah muda-hijau & 0,968 & 0,584 & 3,96 & Tn Tn \\
Hitam-Coklat & 0,252 & 3,288 & 3,96 & Tn Tn \\
Hitam-Hijau & 0,181 & 1,325 & 3,96 & Tn Tn \\
Hitam-Putih & 2,653 & 1,171 & 3,96 & Tn Tn \\
Coklat-Putih & 1,252 & 0,995 & 3,96 & Tn Tn \\
Coklat-Hijau & 0,671 & 0,567 & 3,96 & Tn Tn \\
Hijau-Putih & 2,949 & 0,095 & 3,96 & Tn Tn \\
\hline Keterangan: Tn = Tidak nyata; ${ }^{*}=$ Nyata & &
\end{tabular}

Tabel 3. Pola pertumbuhan berdasarkan diameter dan tinggi cangkang.

\begin{tabular}{lcccc}
\hline \multicolumn{1}{c}{ Populasi } & $\mathbf{b}$ & $\mathbf{t}_{\text {hitung }}$ & $\mathbf{T}_{\text {tab(0,05; 48) }}$ & $\begin{array}{c}\text { Uji t } \\
(\mathbf{b = 1})\end{array}$ \\
\hline Merah muda & 1,136 & 1,021 & 2,012 & $\mathrm{Tn}$ \\
Hitam & 1,222 & 1,207 & 2,012 & $\mathrm{Tn}$ \\
Coklat & 1,171 & 1,021 & 2,012 & $\mathrm{Tn}$ \\
Putih & 1,021 & 0,745 & 2,012 & $\mathrm{Tn}$ \\
Hijau & 1,248 & 0,796 & 2,012 & $\mathrm{Tn}$ \\
\hline
\end{tabular}

Ket.: Tidak nyata (Tn) jika $\mathrm{t}_{\text {hit }}<\mathrm{t}_{\mathrm{tab}}$; Nyata jika $\mathrm{t}_{\text {hit }}>\mathrm{t}_{\text {tab. }}$.

\section{Hubungan Antara Panjang Cangkang dan Lebar Cangkang}

Untuk mengetahui perkembangan individu bulu babi dapat juga dilihat dari pertambahan panjang dan lebar cangkang. Ukuran ini menunjukkan nilai yang bervariasi pada masing-masing populasi warna duri. Kisaran ukuran panjang cangkang populasi warna merah muda adalah $29,38-41,15 \mathrm{~mm}$, hitam 18,67-40,26 mm, coklat 22,12-38,49 $\mathrm{mm}$, putih 21,81-37,32 $\mathrm{mm}$ dan hijau 22,75$36,96 \mathrm{~mm}$. Untuk lebar cangkang warna merah muda 23,59-33,79 mm, hitam 16,54$35,60 \mathrm{~mm}$, coklat $19,96-34,93 \mathrm{~mm}$ dan putih 19,62-34,45 mm, dan hijau 19,11-32,97 mm.

Hasil analisis regresi hubungan panjang-lebar cangkang bulu babi Echinometra mathaei masing-masing populasi warna duri yang diperoleh dalam bentuk transformasi logaritma natural dan kurva perpangkatannya adalah sebagai berikut: 
Pertumbuhan Populasi Bulu Babi

Tabel 4.

\begin{tabular}{|c|c|c|}
\hline Merah muda & $\begin{array}{l}\mathrm{LnL}=0,541+0,787 \mathrm{LnP} \\
\mathrm{L}=1,718 \mathrm{P}^{\mathrm{u}, \text { / }}\end{array}$ & $(n=50 r=0,82)$ \\
\hline Hitam & $\begin{array}{l}\mathrm{LnL}=0,020+0,929 \mathrm{LnD} \\
\mathrm{L}=1,021 \mathrm{P}^{0, y<y}\end{array}$ & $(n=50 r=0,97)$ \\
\hline Coklat & $\begin{array}{l}\mathrm{LnL}=0,030+0,927 \mathrm{LnD} \\
\mathrm{L}=1,031 \mathrm{P}^{0.921}\end{array}$ & $(n=50 r=0,92)$ \\
\hline Putih & $\begin{array}{l}\mathrm{LnL}=0,268+0,858 \mathrm{LnD} \\
\mathrm{L}=1,308 \mathrm{P}^{\mathrm{U.85 \triangleleft}}\end{array}$ & $(n=50 r=0,92)$ \\
\hline Hijau & $\begin{array}{l}\mathrm{LnL}=0,411+0,825 \mathrm{LnP} \\
\mathrm{L}=1,509 \mathrm{P}^{0.1 \angle 5}\end{array}$ & $(n=50 r=0,92)$ \\
\hline
\end{tabular}

Hasil perhitungan koefisien korelasi $(r)$ antara hubungan panjang-lebar cangkang pada kelima populasi warna duri Echinometra mathaei menunjukkan nilai yang cukup besar (mendekati nilai 1) dan positif. Nilai $r$ yang mendekati 1 ini memberikan arti bahwa kedua data ini (panjang-lebar cangkang) memiliki hubungan pendugaan yang sangat kuat (erat). Sedangkan nilai positif menunjukkan bahwa setiap pertambahan ukuran panjang cangkang akan mengalami pertambahan lebar cangkang. Gambar 2 memperlihatkan hubungan antara panjang cangkang pada sumbu $Y$ dan lebar cangkang pada sumbu $X$ pada kelima populasi warna duri.

Hasil analisis keragaman hubungan panjang-lebar cangkang bulu babi Echinometra mathaei tipe $\mathrm{C}$ menunjukkan bahwa nilai $F_{\text {hit }}>F_{\text {tab }(0,05 ; 1 ; 48)}$ yang memberikan arti bahwa data panjang cangkang dapat digunakan untuk menduga data lebar cangkang sampai pada tingkat peluang $95 \%$. Hasil perhitungan tambahan terhadap error ketidakpasan model menunjukkan bahwa nilai $\mathrm{F}_{\text {hit }}<\mathrm{F}_{\mathrm{tab}(0,05 ; 2 ; 42)}$. Hasil ini menunjukkan bahwa data pengamatan dapat digunakan pada model perpangkatan atau model yang dilinierkan.

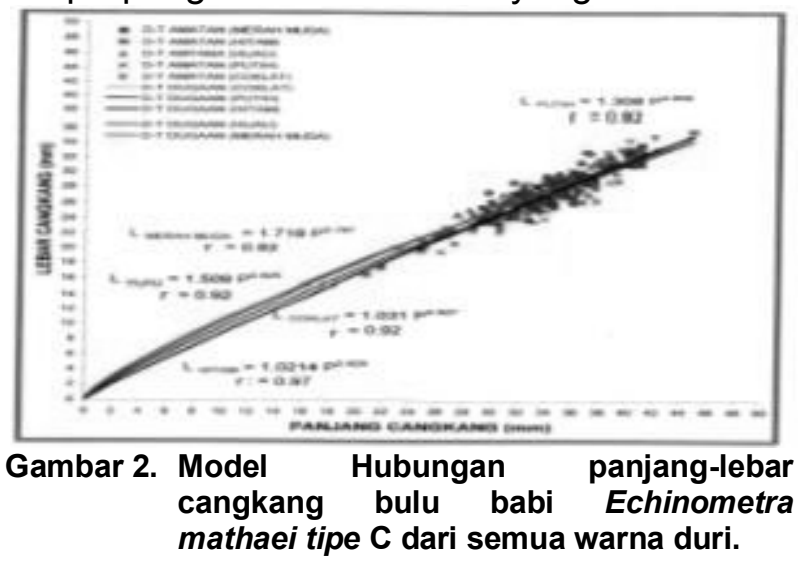

Hasil analisis sepuluh pasangan perbandingan populasi bulu babi Echinometra mathaei (Tabel 5) tidak menunjukkan perbedaan yang nyata untuk uji kemiringan garis regesinya $\left(F_{\mathrm{vm} \text { hit }}<\mathrm{F}_{\operatorname{tab}(0,05} 1,97\right)$, namun untuk uji intersepnya menunjukkan ada 5 pasangan perbandingan populasi warna duri yang menunjukkan perbedaan yang nyata pada tingkat peluang $95 \%$, yaitu populasi warna merah muda-hitam, merah muda-putih, hitam-hijau, coklat-hijau dan hijau-putih. Artinya kelima pasangan populasi ini memiliki perbedaan intersep garis regresi. Sedangkan 5 pasangan perbandingan populasi lainnya, yaitu merah muda-coklat, merah muda-hijau, hitam-coklat, hitam-putih dan coklat-putih tidak menunjukkan perbedaan yang nyata.

Tabel 5. Hasil perbandingan parameter regresi panjang dan lebar cangkang $\left(L=a P^{b}\right)$

\begin{tabular}{lrrrrr}
\hline \multirow{1}{*}{\multicolumn{1}{c}{ Populasi }} & \multicolumn{2}{c}{$\mathrm{F}_{\text {hitung }}$} & $\mathrm{F}_{\text {tabel }}$ & \multirow{2}{*}{$\mathrm{B}$} & \multirow{2}{*}{$\mathrm{a}$} \\
\cline { 2 - 5 } & $\mathrm{F} \mathrm{vm}$ & \multicolumn{1}{c}{$\mathrm{Fv}_{1}$} & 0,05 & & \\
\hline Merah Muda-Hitam & 3,017 & 5,035 & 3,96 & $\mathrm{Tn}$ & $*$ \\
Merah Muda-Coklat & 1,952 & 3,597 & 3,96 & $\mathrm{Tn}$ & $\mathrm{Tn}$ \\
Merah Muda-Putih & 0,536 & 5,207 & 3,96 & $\mathrm{Tn}$ & $*$ \\
Merah Muda-Hijau & 0,175 & 1,314 & 3,96 & $\mathrm{Tn}$ & $\mathrm{Tn}$ \\
Hitam-Coklat & 0,001 & 0,999 & 3,96 & $\mathrm{Tn}$ & $\mathrm{Tn}$ \\
Hitam-Hijau & 3,057 & 13,879 & 3,96 & $\mathrm{Tn}$ & $*$ \\
Hitam-Putih & 1,317 & 0,994 & 3,96 & $\mathrm{Tn}$ & $\mathrm{Tn}$ \\
Coklat-Putih & 0,754 & 1,023 & 3,96 & $\mathrm{Tn}$ & $\mathrm{Tn}$ \\
Coklat-Hijau & 1,707 & 8,413 & 3,96 & $\mathrm{Tn}$ & $*$ \\
Hijau-Putih & 0,194 & 10,419 & 3,96 & $\mathrm{Tn}$ & $*$ \\
\hline Het.: Tn & & & & &
\end{tabular}

Ket.: $\mathrm{Tn}=$ tidak nyata; ${ }^{*}=$ nyata

Berdasarkan uji $t$ (Tabel 6) menunjukkan bahwa populasi bulu babi Echinometra mathaei warna hitam memiliki nilai $t_{\text {hit }}>t_{\operatorname{tab}(0,05 ; 1 ; 48)}$. Artinya populasi bulu babi warna hitam mempunyai pola pertumbuhan allometrik, dan karena $b<1$ maka pola pertumbuhan populasi cenderung allometrik negatif, yang berarti bahwa pertambahan panjang cangkang lebih cepat dari pada pertambahan lebarnya. Keempat populasi warna duri lainnya (merah muda, coklat, putih dan hijau) menunjukkan nilai $t_{\text {hit }}>t_{\operatorname{tab}(0,05 ; 1,48)}$. Artinya pola pertumbuhan panjang dan lebar cangkang populasi keempat warna duri tersebut berjalan dengan laju yang serasi atau pertambahan panjang cangkang seimbang dengan pertambahan lebar cangkang dengan kata lain bahwa tidak terdapat perubahan bentuk (bentuk oval) selama pertumbuhan bulu babi Echinometra mathaei tipe C. Jadi dalam hal ini hanya populasi duri warna hitam saja yang akan mengalami perubahan bentuk cangkang, yaitu ukuran panjang cangkang akan lebih cepat pertumbuhannya dibandingkan dengan ukuran lebar cangkangnya. 
Tabel 5. Pola pertumbuhan berdasarkan hubungan antara panjang dan lebar cangkang.

\begin{tabular}{|c|c|c|c|c|c|}
\hline Populasi & B & $t_{h} ; t$ & $\begin{array}{c}\text { Tabel } \\
0,05\end{array}$ & $\begin{array}{l}\text { Uji t } \\
b=1\end{array}$ & Pola \\
\hline $\begin{array}{l}\text { Merah } \\
\text { muda }\end{array}$ & 0,787 & 0,982 & 2,012 & $\mathrm{Tn}$ & Isometrik \\
\hline Hitam & 0,929 & 2,386 & 2,012 & $\mathrm{~N}$ & Allometrik \\
\hline Coklat & 0,927 & 1,365 & 2,012 & $\mathrm{Tn}$ & Isometrik \\
\hline Putih & 0,858 & 1,481 & 2,012 & $\mathrm{Tn}$ & Isometrik \\
\hline Hijau & 0,825 & 1,620 & 2,012 & $\mathrm{Tn}$ & Isometrik \\
\hline
\end{tabular}

\section{Pembahasan}

Adanya hubungan linier positif baik pada hubungan diameter-tinggi cangkang pada kelima populasi warna duri Echinometra mathaei menunjukkan bahwa setiap pertambahan ukuran diameter cangkang maka akan mengalami pertambahan ukuran tinggi cangkang di mana hubungan masingmasing karakter ukuran ini akan mempengaruhi bentuk cangkang bulu babi. Lumingas dkk., (1996) menyatakan bahwa pada habitat yang terbuka terhadap gelombang, bulu babi memerlukan cangkang yang tabal (berat) dan solid (bentuk bulat).

Pada bulu babi Echinometra mathaei tipe $C$ di rataan terumbuh pantai Kima Bajo, walaupun warnanya bervariasi tetapi karena mereka hidup pada suatu lokasi yang sama maka pengaruh hidrodinamika perairan yang sama akan memberikan pengaruh yang sama terhadap bentuk cangkang mereka. Demikian juga pola pertumbuhan isometrik untuk semua warna bulu babi Echinometra mathaei menunjukkan kondisi lingkungan yang relatif stabil khususnya kondisi hidrodinamika di perairan tersebut selama pertumbuhan bulu babi Echinometra mathaei.

Berbeda dengan hubungan diametertinggi cangkang, hubungan panjang-lebar cangkang bulu babi Echinometra mathaei tipe C menggambarkan bentuk keovalan atau kelonjongan cangkang mereka. Bentuk yang lonjong atau oval dari merupakan suatu adaptasi terhadap kehidupan meliang Echinometra mathaei tipe $\mathrm{C}$ ini sehingga dapat terhindar dari predasi dan juga terhindar dari desikasi (kekeringan) pada saat air surut. Liang yang ditempati bulu babi tersebut dapat juga sebagai perangkap makanan (Lumingas dkk, 1996).

Pola pertumbuhan populasi bulu babi Echinometra mathaei warna duri hitam cenderung allometrik negatif, dimana ukuran panjang cangkang akan lebih cepat pertumbuhannya dibandingkan dengan ukuran lebar cangkang, ini erat kaitan dengan keberadaannya di liang (lubang perlindungan). Hasil pengamatan menunjukkan bahwa populasi warna hitam pada saat pengambilan sampel cenderung lebih banyak ditemukan di dalam liang yang sempit, hal ini jelas mempengaruhi pertumbuhan panjang dan lebar cangkang. Adanya variasi bentuk oval antar warna diduga menunjukkan respon atau adaptasi terhadap bentuk dan kedalaman liang yang ditempati masing-masing populasi bulu babi Echinometra mathaei tipe C.

\section{KESIMPULAN DAN SARAN}

Pola pertumbuhan berdasarkan hubungan diameter-tinggi cangkang seluruh populasi warna (merah muda, hitam, coklat, putih dan hijau diperoleh pertumbuhan isometric, sedangkan pola pertumbuhan berdasarkan hubungan panjang dan lebar cangkang diperoleh dua pola yaitu partumbuhan isometrik untuk populasi warna merah muda, coklat, putih dan hijau, sedangkan untuk pertumbuhan allometrik pada populasi warna hitam. Kegiatan penelitian Ianjutan pola pertumbuhan bulu babi tipe $C$ ditempat lainnya di perairan semenanjung utara Minahasa perlu dilakukan untuk menetapkan variasi pola pertumbuhan bulu babi tipe $C$.

\section{DAFTAR PUSTAKA}

Arakaki, Y dan T. uehara. 1991. Physiological Adaptation of the Four Types of Echinometra mathaei (Blainville). Dalam Yanagisawa, Yasuma, Oguro, Suzuki dan Motokowa. (Eds), Balkema, Roterdam, Hal.105-112.

Birkeland, C. 1988. The Influence of Echinodermata on Coral Reef Communities. Dalam Echinoderm Biology, Burke, R.D, Miadenow, P.V, Lambert, P. dan Parsley, R.L (eds), Balkema, Roterdam. Hal. 1-79.

Effendi, M.I. 1979. Metode Biologi Perikanan. Yayasan Dewi Sri. Bogor. 112 hal.

Huxley, J. S. 1932. Problem of Relative Growth. Methuen. London. 


\section{Pertumbuhan Populasi Bulu Babi}

Hyman, L.H. 1955. Echinodermata in the Invertebrate. Vol. 4. Mc Graw Hill. New York. 763 hal.

Jasin, M. 1987. Sistimatika Hewan (Invertebrata dan Vertebrata). Cetakan ke-1. Penerbit Sinar Widjaja. Surabaya. 324 hal.

Lawrence, J.M. 1975. On the Relationship between Marine Plant and Sea Urchin. Oceanography Marine Biology Ann. Rev. 13: 213-286.

Lawrence J.M. dan P.W. Sammarco. 1982. Effect of Feeding on The Environment: Echinoidea, dalam Echinoderm Nutrition. Jangoux, M. dan J.M. Lawrence. (ed). Balkema, Roterdam. Hal. 499-519.

Lumingas, L.J.L 1994. La Plasticite Chez L'oursia Sphaerechinus granularis En Rade de Brest (Bretagne, France). These. Doct. Universite de Bretagne Occidentale Brest. 193 hal.

Lumingas L.J.L. dan M. Guillou. 1994. Plasticite de l'oursin, Sphaerechinus granularis (Lamarck), face aux variations de l'environnement dalam Echinoderms through time, David, B, Guille, A, Feral, J. P. dan Roux, M (ed.), A.A. Balkema, Rotterdam. Hal. 757-763.

Lumingas, L.J.L., F.B. Boneka, D.A. Sumilat, M. Ompi, dan G.J.F. Kaligis. 1996. Distribusi, Kelimpahan, Struktur Ukuran, dan Morfometri Bulu Babi Diadema savignyi, Echinometra mathaei, Tripneus- tes gratilla (Echinodermata: Echinoidea) di Semenanjung Minahasa. Laporan Penelitian. Fakultas Perikanan. UNSRAT. 109 hal.

Nishihira, M., Y. Sato, Y. Arakaki dan M. Tsuchiya. 1991. Ecological distribution And Habitat areierence of Four Types of Sea Urchin Echinometra mathaei on the Okinawa Coral Reef. Dalam Biology of Echinodermata. Yanagisawa, T., Yasumasu, I., Oguro C., Suzuki, N. dan Motokawa, T. (Eds). Balkema, Roterdam. Hal 91-104.

Scherrer, B. 1984. Biostatistigue. Gaetan Morin Editeur. Boucherville, Canada.

Uehara, T. 1991. Speciation of Indo-Pasific Echinodermata. Dalam Biology of Echinodermata, Yamagisawa, T., Yasumasu, I., Oguro, C., Suzuki, N. dan Motokawa, T. (Eds.). Balkema, Rotterdam. Hal. 139.

Uehara, T., H. Asakura dan Y. Arakaki. 1990. Fertilization, Blockage and Hybridization Among Species of The Sea Urchin. Dalam M. Hoshi dan O. Yamashita (Eds.). Advance in Invertebrata Reproduction. Elsevir Science Publisher B.V. (Biomedical Devision). Amsterdam. Hal 305-310.

Valentine, J.F. dan K.L. Heck. 1991. The Role of Sea Urchin Grazing in Regulating Subtropical Seagrass Meadows: Evidence From Field Manipulations In Northern Gulf of Mexico. J. Exp. Mar. Biol. Ecol. 154:215230. 